\title{
The productivity of GCC Islamic and conventional banks after Basel III announcement
}

\begin{abstract}
Purpose-This study aims to analyse Gulf Cooperation Council (GCC) Islamic and conventional banks' productivity and to investigate the impact of Basel III on their productivity change. This study is conducted on 73 GCC banks (45 conventional and 28 Islamic) over the period of 20052015.Design/methodology/approach-This study uses the data envelopment analysis-type Malmquist productivity change index and its component indexes to obtain a deep insight into the source of productivity change.Findings-The results show that Islamic banks are less productive than their conventional counterparts.Also, the results indicate that Basel III accord has impeded the GCC banks' productivity and this negative effect is larger on Islamic banks. However, there is scale efficiency progress in the past years that offsets the production frontier deterioration, which leads to stagnation in total productivity change for both banks.Originality/value-This study differs from the previous GCC banks' productivity studies in several ways.Firstly, it covers a recent period that includes major events such as the global crisis and focuses on the influence of Basel III accord on GCC banks 'productivity. Secondly, as opposed to the previous studies, this study will estimate the GCC banks' productivity index and its components based on separate frontiers for Islamic and conventional banks that will ensure the homogeneity in the sample and the robustness of the results. Thirdly, this study uses a combination of parametric and nonparametric tests to confirm and check the robustness of the findings. Lastly, to the best of the knowledge of the authors, this is the first study that tries to analyse the GCC banking sector productivity around the new Basel III announcement.
\end{abstract}

Keyword : Basel III; DEA; Islamic banks; GCC banks; Malmquist productivity index 